\title{
The future of cattle veterinary practice: Insights from a qualitative study
}

Hannah Woodward, Kate Cobb, John Remnant

University of Nottingham, School of Veterinary Medicine and Science, Nottingham, UK

Corresponding author:

John Remnant

University of Nottingham

School of Veterinary Medicine and Science

Sutton Bonington Campus

Sutton Bonington

Loughborough

LE12 5RD

John.remnant@nottingham.ac.uk

Tel: 01159516791

Key words: Qualitative research; Veterinary Practice Management; Veterinary Education; Farming; veterinary profession

Word count: 4584 


\section{Abstract}

The British livestock sector is constantly changing due to environmental and economic pressures, consequentially causing a shift in demand on farm veterinary services.

The aim of this study was to explore the future of cattle veterinary practice, using qualitative approach. Telephone interviews were organised with keyopinion leaders within the cattle farm and veterinary sectors, to discuss their opinions on the future of the profession. The interviews were recorded and transcribed, and thematic analysis was used to interpret the data.

The analysis of these interviews resulted in the development of six key themes that emerged as being important in the future of cattle veterinary practice; veterinary business structure, veterinary practice income, collaboration, the changing role of the cattle vet, the vet-farmer relationship, and the new generation of cattle vets.

The study identified that the role of the cattle veterinary practitioner in the UK is changing with an increasing focus on data handling, people management and training, and advisory skills. It is important that these findings are accounted for in the development of undergraduate and postgraduate veterinary training.

\section{Introduction}

Farm veterinary practice in the UK has always evolved alongside the cattle industry. As a result of increasing milk yields ${ }^{1}$, increasing herd sizes ${ }^{2}$, and better business planning, UK dairy farmers have increased efficiency of production by ten per cent over the past ten years. However, there are risks and consequences involved with continually pushing for increased efficiency of 
production on these dairy farms, such as poor health and suboptimal performance ${ }^{3 ;} 4$. This presents new challenges to the farm veterinary profession and explains why these larger dairy units tend to have more of a demand for veterinary services ${ }^{5}$. Such factors have shifted the focus within the profession from traditional emergency work to herd health planning; placing the farm vet in more of an advisory position ${ }^{6}$ although this does have some challenges ${ }^{7}$.

The sale of pharmaceuticals is a major source of income for farm veterinary practice and has been discussed with respect to the farm veterinary business model. Despite the price competition from online pharmacies, practices can still receive significant income from lower medicine margins ${ }^{8}$. The role of paraprofessionals in farm veterinary practice is also effecting the evolution of the farm veterinary business model. Lowe ${ }^{5}$ reported that farmers are looking for a more differentiated service, with technicians taking on more routine roles. It is possible that larger practices could afford to employ paraprofessionals to take on some jobs that the farm vet has traditionally done ${ }^{9}$, allowing the vet to focus on other areas of work such as herd health planning. This would also allow veterinary practices to provide a more diversified service for their clients, delivered by a cost effective team ${ }^{5}$.

These changes need to be considered with respect to veterinary training. The undergraduate veterinary curriculum in the UK is advancing towards 'outcome based' learning; where the course content is designed and driven by learning outcomes that students are then expected to be able to demonstrate at the end of the course ${ }^{10 ; 11 .}$ The trend of increasing numbers of larger practices in place of long-established mixed practices could have a role in encouraging more specialisation before graduation, as the need for omni-competency in practice becomes less and less ${ }^{8}$. These changes may also impact on the provision of and 
need for postgraduate veterinary education, with veterinary graduates choosing to specialise more after graduation.

The way in which the UK cattle farming industry and the veterinary profession work together is changing. To maintain an Outcomes Based Education system, the requirements of the role, and therefore the outcomes, must be reviewed and updated.

The aim of this study was to explore the future role of the cattle vet in the UK, using semi-structured interviews and thematic analysis. Thematic analysis is a widely used method of processing qualitative data and was selected to gain a more in depth understanding of the opinions of key stakeholders ${ }^{12}$. It goes further than organising and describing the data, by identifying, analysing and reporting patterns within a data set ${ }^{13}$.

\section{Materials and Methods}

\section{Interviews}

Interview Design

A series of semi-structured telephone interviews with key opinion leaders in the cattle veterinary and farming sectors were carried out by the author (HW, a veterinary student). An interview guide was developed, informed by significant themes identified in the literature as well as expert opinion. The guide was piloted on two people and a final revised version produced for data collection. The questions explored the participant's opinions on the future role of the cattle vet, how farm practices may change, the influence of technology, and what skills may be important to cattle vets in twenty years' time. Semi-structured interviews use a loose structure based on open-ended questions that define the subject of discussion and allow the interviewer to pursue responses in more detail ${ }^{14}$. 


\section{Interview Participants}

For this study two types of participants were recruited: cattle vets as the providers of veterinary services to farmers, and cattle farmers as the users of veterinary services. Purposive sampling was used to identify participants likely to have an insight into the relevant issues (Table 1).

Potential initial participants were identified using an expert panel and further participants were recruited via snowballing, applying the criteria described in Table 1.

Table 1 Criteria used to identify potential interview participants by purposive sampling

\begin{tabular}{|c|c|}
\hline Respondent & Criteria \\
\hline $\begin{array}{l}\text { Veterinary } \\
\text { Surgeon }\end{array}$ & $\begin{array}{l}\text { - Has worked as a cattle vet in the past } \\
\text { cattle veterinary sector } \\
\text { - Has an interest in how the job will continue to } \\
\text { evolve } \\
\text { - Can provide their informed opinion on the changes } \\
\text { cattle veterinary practice is currently undergoing } \\
\text { and where it may be in the next twenty years }\end{array}$ \\
\hline Farmer & $\begin{array}{l}\text { - An experienced, commercial cattle farmer } \\
\text { - An interest in how the veterinary profession is } \\
\text { - Can share their opinion on what the role of the } \\
\text { cattle vet will look like in twenty years' time, and } \\
\text { why }\end{array}$ \\
\hline
\end{tabular}


Ethical approval was granted by The University of Nottingham and all participants were sent a consent form.

\section{Interview Process}

The interviews were recorded using a mobile phone application (TapeACall).

Data collection continued until saturation was reached,, when no additional information is obtained from the interviews, and therefore no new codes are generated from the data ${ }^{15}$.

\section{Analysis}

Each audio recording was imported and transcribed verbatim by a researcher (HW). Following transcription, thematic analysis was conducted. A deductive approach was used, applying a priori codes formed during literature review and development of the research questions. In addition to these a priori codes, initial codes were also identified using inductive analysis ${ }^{12}$. Collaborative coding was carried out by a second researcher (KC) to check the accuracy and consistency of the coding structure. Following an iterative analytical process, a mind map was built to illustrate the key themes and subthemes identified during the interview process. Transcription and thematic analysis was carried out using NVivo 11 (QSR International).

\section{Results}

\section{Respondent Numbers and Interview Times}

Of seven cattle vets and five cattle farmers contacted, all agreed to participate; a total of twelve participants were interviewed. The cattle vet participants had 
experience within the cattle veterinary industry ranging from thirteen to thirtyone years. The veterinary respondents included RCVS Recognised Specialists working in practice and in consultancy roles as well as senior leaders from corporate and independent veterinary practices. The cattle farmer participants were from dairy and beef farms and included farmers with involvement in industry bodies such as the National Farmers Union (NFU) and the Agriculture and Horticulture Development Board (AHDB), one participant had moved into an advisory role for an independent company. There was a variation in the length of interviews, with the shortest being 7 minutes and 34 seconds, and the longest being 40 minutes and 36 seconds.

\section{Mind Map}

The analysis of these interviews resulted in the development of six key themes which are represented in the mind map shown in Error! Reference source not found. and will be described separately.

\section{Veterinary Business Structure}

This theme arose following the discussion of how the structure of veterinary businesses might change on a larger scale. The rationalisation and consolidation of farm veterinary practice was considered regarding this theme. This is exemplified in the comment from Vet 4:

"there'll be far fewer vet practices... there'll be more consolidation... there will be a couple of bigger players [who will have] a bigger share of the whole market, [and] will be looking after a large number of vets"

Corporatisation was discussed in relation to the similar trend seen in small animal practice and the potential affect this may have on the way veterinary 
businesses operate. Vet 6 spoke about how corporatisation may complement veterinary businesses in the future:

"One is a change in attitude to younger professionals coming through and their vision of where the business can sit and where they wanna sit in the business, and not actually having partnerships but probably corporate businesses, agribusinesses, employing directors and employing fee earners, rather than people being partners in their own business"

\section{Collaboration}

The theme of 'Collaboration' incorporates the alliance of the UK cattle veterinary sector with other related industries. Vet 2 spoke about the importance of having such relationships on a global scale:

"I think what we will find is that we'll have a network of practices.... almost certainly independently owned.... working in networks globally with other vets around the world.... sharing knowledge, skills, resources, expertise, and potentially looking to be on the same platform as our farmers and our suppliers, and by that, I mean our farmers are supplying products onto a global market"

\section{Vet-Farmer Relationship}

This theme emerged from conversations exploring factors that influence the dynamic of the vet-farmer relationship. The cattle vet's role in the understanding and operation of the farm business was considered an important part of this relationship. This is illustrated in a comment made by Farmer 1:

"I think there's certainly something about being able to understand the farmer's business when they turn up... actually having an understanding of the commercial pressure they're under" 
Farmer 3 believed certain pressures meant that farmers would take on some work that the vet traditionally did:

"I can only see us having to become more and more efficient, therefore trying to make savings maybe, through doing more jobs ourselves and, you know, you have to get more and more up-to-date"

They also appreciated the role of the cattle vet and felt the relationship was important to running a successful business:

"I personally think a lot of people do find it really really valuable having a cattle vet to talk to and deal with.... I think the knowledge that they have, in helping you achieve and do what you need to do with the cows, is very important"

Discussion on the subject of technology and data management was frequently linked with the vet-farmer relationship. This is demonstrated by a comment by Farmer 1:

"[The vet] might have even been alerted to problems on the farm through recording of the data, without even the farmer ringing up"

\section{Vet 7:}

"I think a lot of our job is going to be looking at data from various different inputs on the farm... possibly spending less time on the farm and more time... in front of a computer analysing data, and so time actually spent next to a cow is going to be limited compared to what we do now..."

Vet 6 supported the idea that technology will change the type of work cattle vets do: 
"... changes at farm level, through in line milk testing for pregnancies, disease control and disease management, all that's going to change dramatically so that's coming back to the vet being the arbiter of information, rather than the gatherer of information"

The veterinary team and the way that cattle veterinary practices deliver their services was also spoken about in context of the vet-farmer relationship. Vet 2 gave an example of how the role of lay-staff could affect the way cattle vets work with farmers:

"... a lot of vets will still be out every day, scanning cows, doing cows feet, disbudding... which are fairly straight forward technical skills.... [that can be more] cost-effectively done by other people, and those vets can be using their expertise to be working with those farmers on health planning"

Vet 2 continued to comment on the importance the regulation of these paraprofessionals:

".... but the absolute key.... is that it will have to remain and will remain vet led.... they will be working under direction. And that's something we have to work quite closely with the Royal College on actually, is that we don't lose... those [technicians] outside the control of the profession"

\section{Veterinary Practice Income}

This theme developed from discussions on the current sources of income in cattle veterinary practice and how they might change. The importance of medicine sales in veterinary practice was a common topic of discussion.

Vet 2 thought there would be a shift in reliance from medicines sales to income from fees: 
".... we have to get to a point whereby cattle vets are relying on fees and not medicine sales.... I would hope to see the.... ratio to have gone from [in most practices] sixty percent or seventy percent medicines, thirty percent fees, to being the other way around"

Vet 6 developed this idea further by suggesting the sale of medicines to be removed from vets completely, so the practice's income would rely entirely on the other services they provide:

"I would like to see vets... be prescription only, so we actually write the prescriptions and a third party provides the medicines, so the vet's main source of income will actually be the work that they do"

\section{Changing Role of the Cattle Vet}

This theme evolved through discussions about what services farmers might need in the future. The role of the cattle vet as an advisor and consultant was a common topic within the changing role of the cattle vet. Farmer 5 stated:

"I think it will be more... of an advisory than a practical point of view... I see a far more professional relationship between the vet and the herd management, so more structured, less immediate, less reactionary"

Vet 7 supported this idea and linked the change to a professional focus on herd health:

"I think there always will be a role for the farm vet, but I think we're going to become more... consultants than actual practitioners, because I think your individual cow medicine is going to fall by the wayside a little bit, there's gonna be more herd health, rather than individual animal medicine" 
The role of the cattle vet in a training position was considered as a potential future responsibility of the profession. This is exemplified by a comment from Vet 7:

"I think also our job is going to be more about training people on farms to carry out those jobs, better themselves, [...] So I think again that sort of, advisory training type role is probably going to become more important"

Farmer 3 explains how this could benefit cattle farms:

".... if farmers sort of push towards being more and more efficient, and cost of production pricing comes into it... we need to take on more roles ourselves and have vets be telling us how to do those sort of jobs, yeah, maybe even PD'ing comes away from the vet, possibly"

They stated:

"... being able to teach!" would be an important skill.

\section{New Generation}

The 'New Generation' theme evolved following discussion of the future generations of cattle vets and their role in the future development of cattle veterinary practice. Part of this dialogue addressed the new generation's attitude to work-life balance and change in contractual expectations, with respect to the effect this may have on the veterinary practice rotas. Vet 4 suggested:

"... the demands of the vets that are working for farm animal practices will also change... certainly in the small animal side we've already seen it, that people... want to work a four day week, they want to have time off at the weekend, they 
don't want to be doing on call, and I think that's going to be a big challenge for the farm animal practices going forward"

The attitude of veterinary graduates in the cattle veterinary sector was frequently raised in relation to the new generation of cattle vets. Vet 1 connected this disillusionment to the TB testing work load of cattle veterinary practices:

"[Changes allowing vets to stop TB testing], they are so long overdue, they have massively held back farm practice in this country... and it's caused brain drain, it's caused massive disillusionment among graduates. TB testing should not be a vet's job"

The topic of education commonly arose when discussing the new generation of cattle vets. Many participants suggested what skills would be important to the cattle vets of the future and potential changes that could be made to the undergraduate curriculum to ensure the new generation of cattle vets have this skill set. There was a consensus that farm vet graduates needed to have a better understanding of farm business management.

Vet 1: "[Consultancy companies] employ highly intelligent, well-educated graduates that have done agricultural degrees who know a lot about overall farm management and economics, more so, than the average new graduate farm vet knows, and yet, those are essential bits of information that an average UK farm vet should know"

Vet 1 also compared the cattle vet skill set to those of other areas of the profession: 
"... I think [the cattle vets of the future] will need very different skills to what a typical small animal vet will need, because I think increasingly the job is different and for a long time I have believed that it's ridiculous to have a fiveyear course, that is centred on trying to produce an omni-competent mixed practitioner"

\section{Discussion}

The aim of this study was to explore the future role of the cattle vet in the UK, and it has revealed many aspects of cattle veterinary practice that are changing or likely to change in the next twenty years. The objective was to discover what themes would emerge as being important in the future development of the cattle veterinary profession. Key findings include an expected change in the veterinary practice business structure and income, a need for collaboration between the profession and other industries going forward, the effects of new generations of cattle vets on the profession, and how all these factors will combine to shape the role of the cattle vet, and consequently, the vet-farmer relationship.

The results indicated that the role of cattle vet is expected to move towards an advisory and training position. The transition towards a more consultative role is occurring due to several factors and is supported by other work in this area: the rise in preventative herd health planning, and consequential fall in 'firefighter' type work ${ }^{6}$, the increase in average UK herd size and strive for efficiency of production ${ }^{3}$, as well as para-professionals taking on more routine roles such as TB testing and ultra-sound scanning ${ }^{5}$. Equally, an understanding of the farm business should be obligatory for cattle vets, as they take on a consultative role. The results of this study relay the importance of this to farmers: that cattle vets 
cannot only treat sick animals and implement health plans but do so with an understanding of the commercial pressure that farmers are under. The Veterinary Development Council (VDC) released a report in 2012 in response to the recommendations made in The Lowe Report ${ }^{5}$. One of the proposals made in the VDC report was that business education should be incorporated into the teaching of all UK veterinary schools ${ }^{16}$. This would not only encourage an interest in the management of veterinary businesses, but also place the new generation of cattle vets in a better position to give farmers advice concerning aspects of the farm business, thereby maintaining a valuable vet-farmer relationship

The results of this study and related literature concede that, although the cattle vet may eventually become less involved in the treatment of sick cows, their role as herd health advisors and business consultants will become integral to farm management.

Additionally, our results suggest that para-professionals and technicians will continue to have a significant role in cattle veterinary practice, this is also supported by the literature ${ }^{5 ; 8}$. Placing more of an emphasis on interprofessional education ${ }^{17}$ would help facilitate these working relationships and better prepare graduates for working and developing as part of a multi-disciplinary team ${ }^{18}$.

In the results, the use of para-professionals was often raised in conjunction with cost-effective work and providing the vet with more time to focus on other work such as advisory services. Whilst our results highlight the potential benefits of technicians working alongside the veterinary team, previous authors have raised concerns that they must be regulated alongside vets. This is not only to ensure 
welfare standards, but also to discourage technicians from providing their services to farmers separate to the veterinary industry ${ }^{5}$. This situation has already been observed with The Equine Podiatry Association and The National Association of Cattle Foot Trimmers ${ }^{19}$. However in other areas of the equine sector, some equine practices have taken to training and employing physiotherapists and equine dentists as a part of the veterinary team, in an attempt to have a better working relationship with para-professionals ${ }^{20}$. This is also the direction in which cattle practice is developing.

Alongside being an advisor, the results of this study suggest that part of the role of the cattle vet will include the training of farm staff and para-professionals to do certain technical jobs. To effectively carry out this training role, the ability to teach will be important to the cattle vets of the future. The transfer of such teaching skills to medical students was highlighted by The UK General Medical Council as also being important in the training of medical doctors ${ }^{21}$. Therefore, teaching and team management should be considered as skills that are either incorporated into the veterinary curriculum or offered in post-graduate courses. This would put cattle vets in a better position to embrace this training role. Vet schools should place more emphasis on non-technical skills, for example teaching and people management, while considering to what level certain practical skills, such as disbudding and foot trimming, should be incorporated into undergraduate veterinary training, recognising the possibility more of this type of work may be taken on by lay people in the future.

Despite the results suggesting that as the cattle vet begins to deliver more advisory services lay-staff will take on the routine practical work, it is important that cattle vets remain competent with such skills, to be effective team 
managers and teachers. This presents a challenge to veterinary educators $22 ; 23$, trying to retain current skills teaching whilst increasing teaching in new areas.

Advanced technology is already being used to monitor health on an individual and herd basis ${ }^{24}$, especially on high production dairy units ${ }^{25}$. A theme emerging from the data was that such technology could be used to send a continuous stream of data directly to the vet, meaning the performance of a herd could be monitored from the veterinary practice in place of a routine visit, placing the cattle vet in the role of a data analyst. As the use of technology and data collection becomes more significant to the farming industry and veterinary practice, the ability to use technology and handle data will become an essential competence for cattle vets.

Due to the nature of technology and computer programmes, and the speed at which they advance, veterinary schools will need to utilise an OBE approach, to ensure that cattle veterinary graduates remain competent in using the equipment and managing the data required to do the job.

A current topic of debate, which emerged as a theme from the interviews, was veterinary education, and the necessity of the omni-competent design of the current vet school curricula in the UK.

The RCVS Day One Competencies set out the minimum essential competencies expected of all veterinary students to have met upon graduation ${ }^{11}$, and are used by vet schools as a standard guide for the curriculum. The results of this study raise the question as to whether these competencies continue to address the 
requirements of the future farm practitioner. In particular, the areas of interprofessional collaboration and training, an understanding of farm business management, and the use of technology.

As the different areas of veterinary medicine continue to change, alongside the motivations and skills required to work in those fields, time pressures limit the teaching that can be delivered on the veterinary course. In this study some contributors suggested tracking as a potential solution to improving the skill set of graduates. Interestingly, enhancing postgraduate training and continuous professional development provision did not seem to be considered as much.

The tracking model is a potential alternative to the current omni-competent veterinary course, and has been adapted by veterinary schools in other parts of the world; most notably in North America ${ }^{26}$. Such a model enables the provision of more time and resources to teach farm-focussed students the specific skills necessary to work in the production animal industries, such as the cattle sector.

Although past research has shown resistance to increasing tracking in the UK ${ }^{27}$; 28 , the results of this study suggest it may need to be revisited as the required skillsets of farm animal, equine and small animal vets are becoming increasingly diverse. Consequentially, much of the curriculum will be unnecessary to individuals depending on their area of practice. It is worth noting that this need may also be met with postgraduate education rather than tracking at the undergraduate level.

The reflexivity of this study should be considered in terms of the data collected, prior assumptions and experiences can affect the research and research process, 
and therefore shape the data ${ }^{29}$. This can include personal characteristics such as class, race, sex and social distance between the interviewer and the participant. Qualitative studies of this type are interpretative in their nature and prone to researcher bias, therefore a reflexive approach was maintained during data collection and analysis.

Key opinion leaders (KOLs) were selected for the interviews as they are able to provide a unique insight into their area of expertise ${ }^{30}$, and discuss their subject with a more in-depth understanding than other professionals within their field. By selecting a more varied group of participants, alternative opinions may have been discussed and a larger sample required to reach data saturation. This may have led to the emergence of additional themes from the data, however, the aim of this type of study is not to generalise the findings to the wider population, but to identify key themes which others may relate to. Further studies of both other interested groups, for example recent graduates in farm practice and of a wider cross section of the profession would be of value.

Several themes were not evidenced by quotes from farmers: 'veterinary business structure', 'collaboration', 'veterinary practice income' and 'new generation'. Although this could be because these themes are more practice focussed, it does raise the question whether there is a mismatch of expectations between cattle farmers and vets. Further work would be helpful to ascertain how confident vets and farmers feel regarding the areas identified in this study and enable further training to be planned either at undergraduate or postgraduate level. 


\section{Conclusion}

It is clear from the results of this study and related literature, that the direction in which the cattle veterinary profession is heading will inevitably require a skill set different to that of today's cattle vets. The outcomes of the OBE systems will need to change to adapt to this shift in demand. Adapting the undergraduate curriculum as well as postgraduate training provision to what it is graduates need to be competent at, will sufficiently prepare the cattle vets of the future to provide the services that are required of them.

In conclusion, the role of the cattle vet in the UK is changing, with an increasing focus on data handling, people management and training, and advisory skills. It is important that these findings are considered in the development of undergraduate and postgraduate curricula, to ensure the profession continues to adapt alongside the changing cattle industry.

\section{Acknowledgements}

The authors would like to thank all the interviewees for taking the time to participate in the study and for being so willing to share their opinions. The authors would also like to thank Professor Jon Huxley, Dr Wendela Wapenaar and Dr Zoe Belshaw for their advice on the study design and analysis.

\section{References}

1 Bate, A. UK Dairy Industry Statistics 2016.

2 AHDB Dairy Statistics: An insider's guide 2016

3 Sibley, R. Developing health plans for the dairy herd. In Practice 2006;28:114-121

4 Barkema, H. W., von Keyserlingk, M. A. G., Kastelic, J. P., Lam, T. J. G. M., Luby, C., Roy, J. P., LeBlanc, S. J., Keefe, G. P. \& Kelton, D. F. Invited review: Changes in the dairy industry affecting dairy cattle health and welfare. Journal of Dairy Science 2015;98:7426-7445

5 Lowe, P. Unlocking Potential: A report on veterinary expertise in food animal production 2009.

6 Hall, J. \& Wapenaar, W. Opinions and practices of veterinarians and dairy farmers towards herd health management in the UK. Veterinary Record 2012;170 
7 Ruston, A., Shortall, O., Green, M., Brennan, M., Wapenaar, W. \& Kaler, J. Challenges facing the farm animal veterinary profession in England: A qualitative study of veterinarians' perceptions and responses. Preventive Veterinary Medicine 2016;127:84-93

8 Statham, J. \& Green, M. Cattle veterinary services in a changing world. Veterinary Record 2015;176:276-280

9 Anon. Future of farming and farm veterinary practice. Veterinary Record 2006;159:577

10 H Davis, M., Amin, Z., Grande, J., E O'Neill, A., Pawlina, W., R Viggiano, T. \& Zuberi, R. Case studies in outcome-based education. Medical Teacher 2007;29:717-722

11 RCVS. RCVS Day One Competencies 2014.

12 Braun, V. \& Clarke, V. Using thematic analysis in psychology. Qualitative Research in Psychology 2006;3:77-101

13 McDermott, M. P., Cobb, M. A., Tischler, V. A., Robbé, I. J. \& Dean, R. S. Evaluating veterinary practitioner perceptions of communication skills and training. Veterinary Record 2017;180:305-305

14 Britten, N. Qualitative Interviews. In Qualitative Research in Healthcare. Eds C. Pope \& N. Mays. Blackwell Publishing Ltd 2006

15 Fusch, P. I. \& Ness, L. R. Are We There Yet? Data Saturation in Qualitative Research. The Qualitative Report TQR 2015;20

16 VDC. The Veterinary Council Development Report 2011-2012. 2012.

17 Bridges, D. R., Davidson, R. A., Odegard, P. S., Maki, I. V. \& Tomkowiak, J. Interprofessional collaboration: three best practice models of interprofessional education. Medical education online 2011;16:10.3402/meo.v3416i3400.6035

18 Kinnison, T., Lumbis, R., Orpet, H., Welsh, P., Gregory, S. \& Baillie, S. Piloting Interprofessional Education Interventions with Veterinary and Veterinary Nursing Students. Journal of Veterinary Medical Education 2011;38:311-318

19 Atkinson, O. National Association of Cattle Foot Trimmers. Veterinary Record 2005;157:298-298

20 Mayes, B. Changes affecting the equine sector. Veterinary Record 2015;176:457

21 Shariq, O., Alexopoulos, A.-S., Razik, F., Currie, J. \& Salooja, N. Teaching skills training for medical students. The Clinical Teacher 2013;10:146-150

22 May, S. A. Modern veterinary graduates are outstanding, but can they get better? J Vet Med Educ 2008;35:573-580

23 Jackson, E. L. \& Armitage-Chan, E. The Challenges and Issues of Undergraduate Student Retention and Attainment in UK Veterinary Medical Education. J Vet Med Educ 2016;44:247-259

24 Loeb, J. How technology can help livestock farming. Veterinary Record 2018;183:7-7

25 Eastwood, C., Jago, J., Edwards, P. \& K. Burke, J. Getting the most out of advanced farm management technologies: Roles of technology suppliers and dairy industry organisations in supporting precision dairy farmers. Animal Production Science 2015;56

26 Klosterman, E. S., Kass, P. \& Walsh, D. A. Approaches to veterinary education - Tracking versus a final year broad clinical experience. Part one: Effects on career outcome. 2009

27 Crowther, E., Hughes, K., Handel, I., Whittington, R., Pryce, M., Warman, S., Rhind, S. \& Baillie, S. Stakeholder consultation on tracking in UK veterinary degrees: part 1. Veterinary Record 2014;175:8686

28 Crowther, E., Hughes, K., Handel, I., Whittington, R., Pryce, M., Warman, S., Rhind, S. \& Baillie, S. Stakeholder consultation on tracking in UK veterinary degrees: part 2. Veterinary Record 2014;175:8787

29 Mays, N. \& Pope, C. Quality in qualitative health research In Qualitative Research in Healthcare. Eds C. Pope \& N. Mays. Blackwell Publishing. pp 892006

30 Capper, M. White Paper: Use of Key Opinion Leaders (KOLs) in Healthcare, Medical Devices and Pharmaceuticals. $\quad$ https://www.linkedin.com/pulse/white-paper-use-key-opinion-leaders-kolshealthcare-medical-capper. Accessed 2016 